\title{
High- and Low-Rearing Rats Differ in the Brain Excitability Controlled by the Allosteric Benzodiazepine Site in the $\mathrm{GABA}_{\mathrm{A}}$ Receptor
}

\author{
Rosana Alves, José Gilberto Barbosa de Carvalho, Marco Antonio Campana Venditti* \\ Departamento de Psicobiologia, Escola Paulista de Medicina, Universidade Federal de São Paulo, \\ Rua Botucatu, Brazil \\ Email: ${ }^{*}$ macvenditti09@unifesp.br
}

Received April 20, 2012; revised May 9, 2012; accepted May 30, 2012

\begin{abstract}
Rearing is an exploratory behavior induced by novelty, such as exposure to an open field. Stimulation of certain brain regions, including the hippocampus, induces both rearing and clonic convulsions. Brain excitability is controlled by gamma-aminobutyric acid (GABA) inhibitory neurotransmission through its ionotropic $\mathrm{GABA}_{\mathrm{A}} /$ allosteric benzodiazepine site. Drugs that decrease $\mathrm{GABA}_{\mathrm{A}}$ receptor fast inhibitory neurotransmission induce clonic convulsions and rearing when injected into the hippocampus. Therefore, individual differences in rearing behavior may be related to the susceptibility to clonic convulsions, which could involve differences in brain excitability controlled by GABA $/$ /allosteric benzodiazepine site receptors. Adult, male Wistar rats were divided into high- (HR) and low-rearing (LR) groups based on the number of rearings in the open field test. Groups of HR and LR rats were challenged with convulsant drugs that antagonize GABA neurotransmission via different mechanisms of action (3-mercaptopropionic acid, a glutamate decarboxilase inhibitor; bicuculline, a $\mathrm{GABA}_{\mathrm{A}}$ receptor antagonist; pentylenetetrazol and picrotoxin, both $\mathrm{GABA}_{\mathrm{A}}$ receptor chloride channel blockers and DMCM, a benzodiazepine inverse agonist). The convulsant doses that induced $50 \%$ of clonic convulsions were determined for each drug. The LR rats had a higher susceptibility (a lower convulsant dose $50 \%$ ) to clonic convulsions induced by DMCM than the HR rats, but there were no differences between the groups in the susceptibility to tonic convulsions induced by the same drug. There were no significant differences in the convulsant dose $50 \%$ for clonic convulsions between the groups for all other drugs injected. In another experiment, additional HR and LR rats were injected with a sedative-hypnotic dose of diazepam, which caused a significantly higher hypnotic effect (sleeping-time) in the LR rats than in the HR rats. The LR group was also shown to have a significantly lower density of $\left[{ }^{3} \mathrm{H}\right]$-Flunitrazepam bound to the $\mathrm{GABA}_{\mathrm{A}}$ receptor in hippocampal membranes. Our data suggest that inter-individual differences in rearing are related, at least in part, to the GABA inhibitory neurotransmission controlled by the benzodiazepine allosteric site in the $\mathrm{GABA}_{\mathrm{A}}$ receptor.
\end{abstract}

Keywords: Open Field; Rearing Behavior; Clonic Convulsion; Diazepam; Sleep; Benzodiazepine; DMCM; GABA Receptor; $\left[{ }^{3} \mathrm{H}\right]$-Flunitrazepam Binding; Hippocampus; Novelty; Stress

\section{Introduction}

The open field is a widely used behavioral test, with rearing being one of the most commonly recorded behaviors. Rearing is considered an exploratory behavior evoked by novel stimuli [1-3]. Exploratory behavior is an important aspect of the behavioral repertoire of an individual because, despite the increased risk of facing a predator, it increases the knowledge of the environment and thereby increases the chances of finding food, mates and shelter.

Rearing has been shown to correspond with hippocampal electrical activity. For instance, strains of rats

"Corresponding author. differing in the number of open field rearings also differ in their hippocampal EEG power with a higher frequency of rearings corresponding with a higher EEG hippocampal power [4]. Changes in the frequency of rearing behavior have been observed under experimental conditions, such as electrical brain stimulation [5-8] and drug treatment [9]. Kindling, which is an experimental procedure involving the delivery of an initially subconvulsive electrical stimulus to certain brain areas that then becomes convulsive after a series of stimulation sessions, results in the appearance of clonic convulsions and rearing [8]. In rats kindling to the dorsal hippocampus induced an increase in the number of open-field rearings [5]. In mice, hippocampal mossy fiber distribution has 
been implicated in exploratory behavior and rearing [1, 10]. Mice from different inbred strains, as well as strains genetically selected for high- (HR) and low-rearing (LR) behavior, showed differences in their hippo-campal morphologies with higher rearing strains having larger intra- and infra-pyramidal mossy fiber projections [1113].

Behavior can be considered the output of interacting inhibitory and stimulatory synaptic mechanisms that occur in the central nervous system. Gamma-aminobutyric acid (GABA), considered the most important inhibitory neurotransmitter in the vertebrate brain, controls the level of brain excitability by interactions with its ionotropic and metabotropic receptors [14-17]. GABA fast synaptic inhibitory action is achieved by the interaction of the neurotransmitter with its ionotropic $\mathrm{GABA}_{\mathrm{A}}$ receptor, which has several binding sites, including a GABA binding site, an allosteric chloride channel binding site and a benzodiazepine binding site. Drugs that act on these binding sites, thereby promoting a decrease in the GABA/ $\mathrm{GABA}_{\mathrm{A}}$ interaction, are convulsants, including bicuculline, picrotoxin and benzodiazepine inverse agonists $[15,18,19]$. Drugs that inhibit GABA synthesis are also convulsants $[18,20]$. In contrast, benzodiazepine agonists, which have several effects, are potent anticonvulsant drugs [21] that are largely used in the clinic [22]. A quantitative trait loci (QTL) study in mice identified two QTLs that colocalized on chromosome 10, one for convulsion susceptibility induced by beta-CCM, a convulsant that acts as an inverse agonist at the $\mathrm{GABA}_{\mathrm{A}}$ /benzodiazepine allosteric site [23] and the other for rearing in the open field, which suggested the existence of a single locus with a pleiotropic effect [24]. Therefore, the inter-individual differences in rearing behavior may be due to differences in the expression of $\mathrm{GABA}_{\mathrm{A}} /$ benzo- $^{-}$ diazepine ionotropic receptors in the brain.

We have shown that rats divided into HR and LR groups based on their responses in the open field have differing $\mathrm{K}^{+}$-stimulated $\mathrm{p}$-nitrophenylphosphase hippocampal activity [23]. This activity involves the reaction to the dephosphorylation of phosphorylated $\mathrm{Na}^{+}, \mathrm{K}^{+} / \mathrm{AT}$ Pase, which is responsible for maintaining and restoring the higher extracellular $\mathrm{Na}^{+}$and intracellular $\mathrm{K}^{+}$levels, that are necessary for action potential generation [24-26]. The low rearing group has a lower enzymatic activity in the hippocampus, which is an indication of a difference in brain excitability between the groups [23]. A recent study involving extra- and intra-cellular recordings on rat hippocampal slices showed a hyperexcitability induced by the partial inhibition of $\mathrm{Na}^{+}, \mathrm{K}^{+} /$ATPase with dihydroouabain, which induces interictal-like epileptiform bursting activity [27]. Moreover, the subsequent use of the $\mathrm{GABA}_{\mathrm{A}}$ receptor channel blocker, picrotoxin, in that study indicated that reduced GABAergic potentials and enhanced excitatory postsynaptic potentials and spike firing were the primary mechanisms underlying the hyperexcitability associated with impaired $\mathrm{Na}^{+}, \mathrm{K}^{+} /$ATPase activity [27]. Based on these data, the LR group rats would be expected to have a higher sus- ceptibility to convulsions.

The main goal of this work was to determine whether rats designated as either HR or LR, based on their response in the open field, differed in the brain excitability controlled by the $\mathrm{GABA}_{\mathrm{A}} /$ allosteric benzodiazepine site receptor. We have included in this report other experiments which we think may be relevant to the differences of rearing in the rats.

\section{Methods}

\subsection{Subjects}

Naïve adult (3 months old), outbred male Wistar rats from our own breeding colony were used in the experiments. After weaning at 21 days the rats were kept in polypropylene cages $(60 \times 50 \times 22 \mathrm{~cm}, 5-6$ rats $/$ cage $)$ in a room with a controlled temperature $\left(22^{\circ} \mathrm{C} \pm 2^{\circ} \mathrm{C}\right)$ and light-dark cycle (lights on from 7:00 a.m. to 7:00 p.m.). The rats had free access to water and Purina ${ }^{\circledR}$ chow pellets at all times. Routine food, water delivery and cage cleaning were the only manipulations until the rats were submitted to the experimental procedures.

This work was approved by our institution ethics committee on animal research (proc. \# 0938/03).

\subsection{Open Field Test}

The open field apparatus used in this work has been described in detail previously [28]. Briefly, it consists of a round arena $(80-\mathrm{cm}$ diameter, $30-\mathrm{cm}$ height $)$ with the floor divided into three concentric circles and illuminated by six light bulbs ( $60 \mathrm{~W}$ each) positioned above the arena. The open field sessions for these experiments did not employ a sound stimulus.

For each drug test a different set of rats was submitted to the open field test for selection of the HR and LR groups. On the day of the open field experiment the rats were removed from the stock room to another room near the open field. Each rat was carried in a small cage to the open field room and submitted to a 3-min session in the open field. The total number of rearings and ambulation (number of floor divisions crossed with the four paws) were scored.

After the open field session, the rat was returned to its home cage, and the test apparatus was cleaned with diluted ethanol before the next animal was tested. All open field tests were carried out between 1:00 and 5:00 p.m. to keep any possible circadian influences constant [28]. The rats remained for about $15-20$ days in the stock room with no other disturbances but cage cleaning and water 
and food delivery.

To determine if rearing behavior in the open field has a normal distribution in rats, a large group of rats $(\mathrm{N}=70)$ was statistically analyzed. The statistical analysis showed that rearing indeed has a normal distribution and was able to pass the normality test $(\mathrm{p}=0.05)$. The mean \pm S.E.M. was $24.0 \pm 1.0$ and the median was 25 rearings ( 25 th percentile $=18$ rearings and 75 th percentile $=30$ rearings). Rats showing $\leq 18$ rearings were assigned to the LR group and those showing showing $\geq 30$ rearings were assigned to the HR group.

\subsection{Drug Administration}

After a 20-day rest period following the group assignments, different groups of the HR and LR rats were challenged with one of several different drugs. At least three different doses were tested for each drug. The rats (8 - 10 rats/group/dose, except the LR group injected with 3-MP for which 5 - 6 rats/dose were used) were moved to a quiet room to prevent any unnecessary disturbances. After weighing and drug injection, the rats were observed in wired cages (one rat/cage) for $45 \mathrm{~min}$ to monitor for the appearance of clonic convulsions and other convulsive symptoms. All drug test sessions were carried out during the afternoon (1:00 to 5:00 p.m.) to avoid possible circadian influences [28]. Each rat received only one dose of each drug tested. To avoid differences in rearing the HR and LR rats were randomly assigned to each dose of the convulsant drug being tested. The convulsant dose that produced $50 \%$ of full clonic convulsions in the HR and LR groups was calculated using the method described by Litchfield and Wilcoxon [29]. Each convulsant dose $50 \%(\mathrm{mg} / \mathrm{kg}$ body weight) is presented with its 19/20 upper and lower confidence limits.

\subsection{Hypnotic Sensitivity}

Other groups of the HR (32.2 \pm 0.6 rearings, mean \pm S.E.M., $\mathrm{N}=9)$ and LR $(13.5 \pm 0.7$ rearings, mean \pm S.E.M., $\mathrm{N}=13)$ rats were injected with diazepam (8 $\mathrm{mg} / \mathrm{kg}$, i.p.), and the sleep time which was defined as the the time interval between the loss and recovery of the righting reflex was scored [30]. Following the intraperitoneal injection of Diazepam the rats becoming ataxic were placed on their backs and those failing to right themselves three times in 20 seconds were considered to be asleep. When the rats were able to right themselves three times in 20 seconds, the measure of hypnotic effect was over.

\subsection{Influence of Stress on Rearing Behavior}

The illuminated open field apparatus used in our study can be considered a stressful stimulation. Therefore, differences in the stress reaction between individuals could influence the appearance of rearings and thus the difference in the frequency of rearing between the HR and LR groups. To determine whether different levels of stress would have an effect on the rearing behavior, two groups of naïve rats were submitted to a 3-min session in the open field; one group with only the artificial illumination of the room on (three $40-\mathrm{W}$ fluorescent lamps fixed to the ceiling) and the other with the open field illumination on (six $60-\mathrm{W}$ light bulbs) plus the artificial illumination of the room.

\subsection{Effects of Open Field Re-Test on HR and LR Groups}

To determine the stability of the differences in rearing behavior between the HR and LR groups, HR (33.6 \pm 1.3 rearings, mean \pm S.E.M., $\mathrm{N}=10)$ and $\mathrm{LR}(14.7 \pm 1.3$ rearings, mean \pm S.E.M., $\mathrm{N}=7$ ) rats were re-submitted to another open field session 15 days after the initial open field selection session.

\subsection{Influence of Stress Hormones (ACTH and Corticosterone) on Rearing Behavior}

Differences in the basal levels of stress hormones could account for behavioral differences due to the effects of the hormone in the brain [31]. The plasma ACTH and serum corticosterone levels were measured in the HR and LR rats to determine if the levels of these stress hormones differed between the two groups. The rats from these HR and LR groups were not submitted to any other treatment except to the initial open field test selection session. During a 20-day rest period, after the open field session, the rats were not habituated to the handling necessary to sacrifice the animals; therefore, the stress hormones levels were measured in a situation where the handling necessary to sacrifice the rats was the only stimulus. Each rat was individually moved to another room (one HR rat followed by one LR rat) and rapidly guillotined and the trunk blood was collected. Plasma ACTH was assayed by a sequential chemiluminescence immunometric method using a monoclonal murine antibody specific for ACTH (DPC Immulite, Los Angeles, CA, USA) and serum corticosterone was assayed by a double antibody RIA method using a commercial kit specific for rats and mice (ICN Biomedicals, Costa Mesa, CA, USA). Both methods have been previously used in our laboratory $[32,33]$.

\section{8. $\left[{ }^{3} \mathrm{H}\right]$-Flunitrazepam $\left.\left({ }^{3} \mathrm{H}\right]-\mathrm{FNT}\right)$ Binding}

HR and LR rats were guillotined followed by the rapid excision of their brains. The hippocampus was dissected 
while keeping the brains on a cooled Petri dish placed on crushed ice. The hippocampi were kept frozen $\left(-20^{\circ} \mathrm{C}\right)$ until the preparation of the homogenates.

The homogenates were prepared in a glass tube in cold sucrose $\left(0.32 \mathrm{M}, \mathrm{pH}\right.$ 7.4) using a Teflon ${ }^{\circledR}$ pestle driven by an electric motor. The homogenates were centrifuged at $900 \mathrm{x} \mathrm{g}$ for $10 \mathrm{~min}$ at $4^{\circ} \mathrm{C}$. The supernatants were collected and centrifuged at $30,000 \times \mathrm{g}$ for $30 \mathrm{~min}$ at $4^{\circ} \mathrm{C}$. The pellets were resuspended in Tris/ $\mathrm{HCl}$ buffer $(50 \mathrm{mM}$, $\mathrm{pH}$ 7.4). After another centrifugation at $30,000 \mathrm{x} \mathrm{g}$, the supernatants were discarded, and the pellets were kept frozen $\left(-20^{\circ} \mathrm{C}\right)$ until the binding assay.

For the binding assay the pellets were resuspended in cold Tris/HCl buffer $(100 \mathrm{mM}, \mathrm{pH} 7.7)$ and the density of $\left[{ }^{3} \mathrm{H}\right]$-FNT $(70-87 \mathrm{Ci} / \mathrm{mmol}$, PerkinElmer Life and Analytical Science) was determined as previously described [34]. Briefly, the total binding assay was carried out in a total volume of $150 \mu \mathrm{l}$ in the presence of

$\left[{ }^{3} \mathrm{H}\right]$-FNT (1.4 or $3.6 \mathrm{nM}$ ) and nonspecific binding was determined in the presence of cold DMCM $(7.5 \mu \mathrm{M})$. The samples were incubated for $30 \mathrm{~min}$ at $0^{\circ} \mathrm{C}-4^{\circ} \mathrm{C}$. The incubation was terminated by rapid vacuum filtration using Whatman GF/B filters. Specific binding was obtained by subtracting the nonspecific binding from total binding.

The results of the binding assays are expressed as fmol of $\left[{ }^{3} \mathrm{H}\right]-\mathrm{FNT}$ bound $/ \mathrm{mg}$ protein. The proteins were assayed according to Lowry et al. [35] using bovine serum albumin as the standard.

\subsection{Drugs}

The following convulsant drugs were used in this study: bicuculline (BIC) (subcutaneously [s.c.]), a $\mathrm{GABA}_{\mathrm{A}}$ receptor antagonist; picrotoxin (PIC) (intraperitoneally [i.p.]) and pentylenetetrazol (PTZ) (i.p. or s.c.), both $\mathrm{GABA}_{\mathrm{A}}$ receptor chloride channel blockers;

methyl-6,7-dimethoxy-4-ethyl-b-carboline-3-carboxamide (DMCM) (i.p.), a benzodiazepine inverse agonist $[15,36$, 37] and 3-mercaptopropionic acid (3-MP) (i.p.), a glutamate decarboxylase competitive inhibitor [20]. 3-MP and PTZ were diluted in saline, PIC was diluted in warmed saline, and BIC and DMCM were first dissolved in a few drops of $1 \mathrm{~N} \mathrm{HCl}$ and then diluted in saline. The drugs were injected in a volume of $0.1 \mathrm{ml} / 100 \mathrm{~g}$ body weight. All convulsant drugs were obtained from Sigma Chemical Company. Diazepam $\left(\right.$ Valium $\left.^{\circledR}\right)$ was obtained commercially.

\subsection{Statistics}

The open field measures were analyzed using the MannWhitney U test. Sleeping-time, $\left[{ }^{3} \mathrm{H}\right]$-FNT binding, ACTH levels and corticosterone levels were analyzed using the unpaired Student's $t$ test. The level of significance for two-tailed analyses was set at $\mathrm{p} \leq 0.05$. Convulsant doses $50 \%$ were calculated and compared according to Litchfield and Wilcoxon [29].

\section{Results}

\subsection{Selection of HR and LR Groups in the Open Field}

The means \pm S.E.M. of the rearings in the naïve, outbred, strain of Wistar rats (Total) used to select HR and LR rats and the means \pm S.E.M. of the rearings in selected HR and LR groups of rats are given in Table 1. The number of rearings did not vary significantly between several litters that were tested during different months of the year. In addition, the different HR and LR groups consistently showed comparable numbers of rearings during the open field selection sessions $(\mathrm{p}<0.001$, twotailed, Mann-Whitney U test). In some HR and LR subgroups the HR subgroup of rats ambulated significantly more than the LR rats (Table 1).

\subsection{Susceptibility to Clonic Convulsions in HR and LR Rats}

The convulsant dose $50 \%$ for the clonic convulsions produced by each of the convulsant drugs is shown in Figure 1 and Table 2. The HR and LR rats differed in the susceptibility to clonic convulsions induced by DMCM, with LR rats requiring a significantly lower convulsant dose $50 \%$ than HR rats, (potency ratio $=1.24[1.12$ 1.36 ], $\mathrm{p}<0.05$, Figure 1). In contrast, the DMCM convulsant dose $50 \%$ required to induce tonic convulsions was not different between the $\mathrm{HR}\left(\mathrm{CD}_{50} 0.88 \mathrm{mg} / \mathrm{kg}\right.$ $[0.81-0.96] \pm 19 / 20$ confidence limits $)$ and $\mathrm{LR}\left(\mathrm{CD}_{50}\right.$ $0.86 \mathrm{mg} / \mathrm{kg}[0.77-0.96])$ rats.

There were no significant differences between the HR and LR groups with respect to the induction of clonic convulsions for any of the other convulsant drugs tested (Table 2).

\subsection{Loss of Righting Reflex in the HR and LR Rats}

Diazepam induced a significantly longer sleeping time in LR rats (Figure 2) $(\mathrm{t}=2.150, \mathrm{df}=20, \mathrm{p}=0.04$, twotailed, unpaired Student's $t$ test).

\subsection{Stress Levels and Rearing}

The number of rearings was not influenced by different stimulation levels in the open field test (Table 3). There were no differences in the number of rearings performed by the rats tested with the open field lights on and by the rats tested with the open field lights off ( $p>0.05$, twotailed, Mann-Whitney U test). Moreover, the mean number of rearings obtained in either situation (lights on and 
Table 1. Selection of high- (HR) and low-rearing (LR) rats in the open field test.

\begin{tabular}{|c|c|c|c|c|c|c|}
\hline \multicolumn{7}{|c|}{ Rearings } \\
\hline & DMCM (i.p.) & 3-MP (i.p.) & PTZ (s.c.) & PTZ (i.p.) & PIC (i.p.) & BIC (s.c.) \\
\hline \multirow[t]{2}{*}{ HR } & $32.9 \pm 1.2$ & $35.5 \pm 0.9$ & $37.5 \pm 1.5$ & $34.5 \pm 1.1$ & $34.6 \pm 1.0$ & $33.6 \pm 0.8$ \\
\hline & (35) & (31) & (25) & (35) & (31) & (35) \\
\hline \multirow[t]{2}{*}{ LR } & $14.7 \pm 0.8^{\mathrm{d}}$ & $15.4 \pm 0.7^{\mathrm{d}}$ & $13.5 \pm 0.7^{\mathrm{d}}$ & $13.6 \pm 0.7^{\mathrm{d}}$ & $17.9 \pm 0.5^{\mathrm{d}}$ & $15.4 \pm 0.6^{\mathrm{d}}$ \\
\hline & (29) & (17) & (17) & (35) & (37) & (29) \\
\hline \multirow[t]{3}{*}{ Total } & $24.4 \pm 0.9$ & $26.8 \pm 1.0$ & $23.6 \pm 1.2$ & $24.0 \pm 1.0$ & $23.9 \pm 0.9$ & $24.8 \pm 0.9$ \\
\hline & (100) & (70) & (85) & (96) & (101) & (94) \\
\hline & \multicolumn{6}{|c|}{ Ambulation } \\
\hline HR & $72.4 \pm 3.8$ & $72.3 \pm 4.1$ & $65.7 \pm 3.2$ & $68.3 \pm 2.7$ & $70.4 \pm 3.0$ & $73.0 \pm 2.8$ \\
\hline LR & $61.5 \pm 3.8^{\mathrm{c}}$ & $61.4 \pm 5.9$ & $56.2 \pm 4.3^{\mathrm{a}}$ & $59.7 \pm 3.0^{\mathrm{b}}$ & $62.8 \pm 3.2$ & $74.9 \pm 4.1$ \\
\hline \multirow[t]{2}{*}{ Total } & 7.32 .0 & 51.72 .6 & 59.92 .1 & 65.11 .8 & 67.21 .9 & 72.02 .0 \\
\hline & (100) & (70) & (85) & (96) & (101) & (94) \\
\hline
\end{tabular}

The values are expressed as the means \pm S.E.M. Total $(\mathrm{N})$ number of rats used to select the $\mathrm{HR}$ and $\mathrm{LR}$ rats for each convulsant drug experiment. (n) number of rats used in each experiment. DMCM: methyl-6,7-dimethoxy-4-ethyl-b-carboline-3-carboxamide; 3-MP: 3-mercaptopropionic acid; BIC: bicuculline; PIC: picrotoxin; PTZ: pentylenetetrazol. s.c.: subcutaneous, i.p.: intraperitoneal. (a) $p=0.03$; (b) $p=0.04$; (c) $p=0.05$; (d) $p=0.001$.

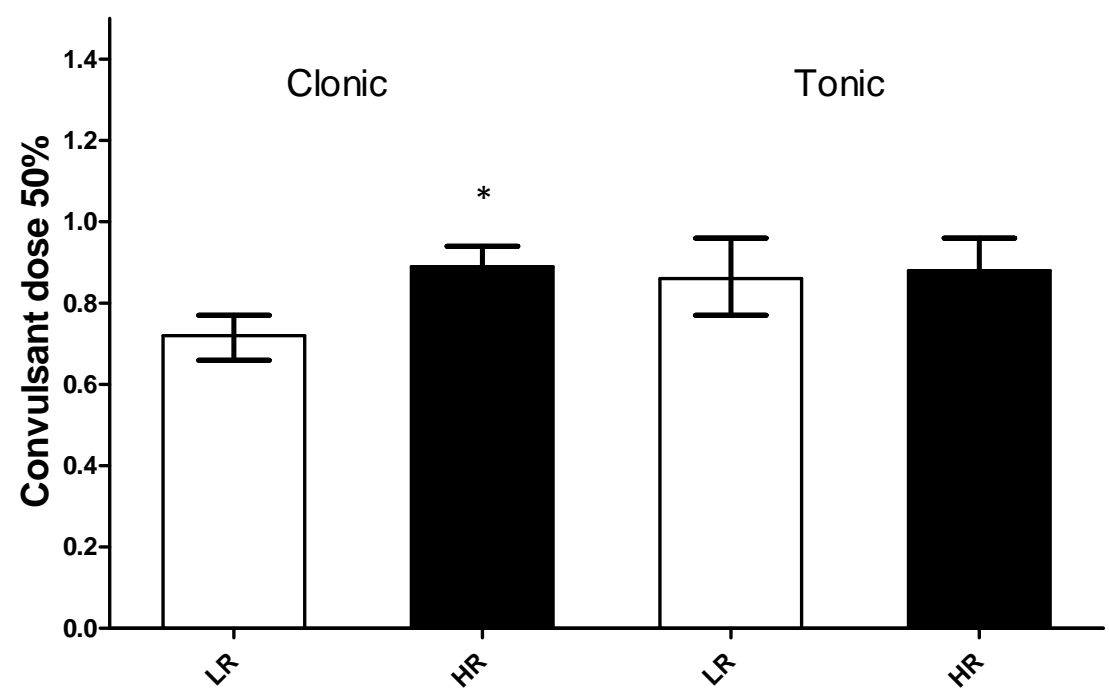

Figure 1. Convulsant dose $50 \%$ (19/20 confidence limits) for clonic and tonic convulsions induced by DMCM in high- (HR) and low-rearing (LR) rats. The HR and LR rats were injected with DMCM intraperitoneally $(8-10$ rats/dose/group, $\mathrm{N}=35$ for HR rats and $N=29$ for LR rats). Each rat was injected with DMCM only once. The convulsant dose $50 \%$ calculated and compared according to Litchfield and Wilcoxon [35]. ${ }^{*} \mathrm{p}=\mathbf{0 . 0 5}$.

Table 2. Convulsant dose $\mathbf{5 0 \%}$ for clonic convulsions induced by drugs that decrease GABAergic neurotransmission in high(HR) and low-rearing (LR) rats.

\begin{tabular}{cccccc}
\hline & \multicolumn{3}{c}{ Drugs } \\
\hline Group & 3 -MP & PTZ (s.c.) & PTZ (i.p.) & PIC & BIC \\
HR & 17.5 & 40.0 & 29.0 & 3.0 & 1.9 \\
& $(15.2-20.1)$ & $(38.0-42.0)$ & $(26.0-32.0)$ & $(2.6-3.5)$ & $(1.7-2.1)$ \\
LR & 17.0 & 40.0 & 28.0 & 3.2 & 2.1 \\
& $(15.1-19.0)$ & $(36.7-43.6)$ & $(25.0-31.0)$ & $(2.7-3.8)$ & $(1.9-2.2)$ \\
\hline
\end{tabular}

3-MP: 3-mercaptopropionic acid; PTZ: pentylenetetrazol; PIC: picrotoxin; BIC: bicuculline; s.c.: subcutaneous; i.p.: intraperitoneal. PIC and 3-MP were administered i.p. and BIC s.c. For each drug and rat group at least three doses of each drug were tested $(8-12$ rats/dose/group, except for LR subgroup injected with 3-MP, which was 5 - 6 rats/dose). Each rat was injected with only one dose of the convulsant drug tested. Numbers in the Table represent the convulsant dose $50 \%$ (19/20 confidence limits). 


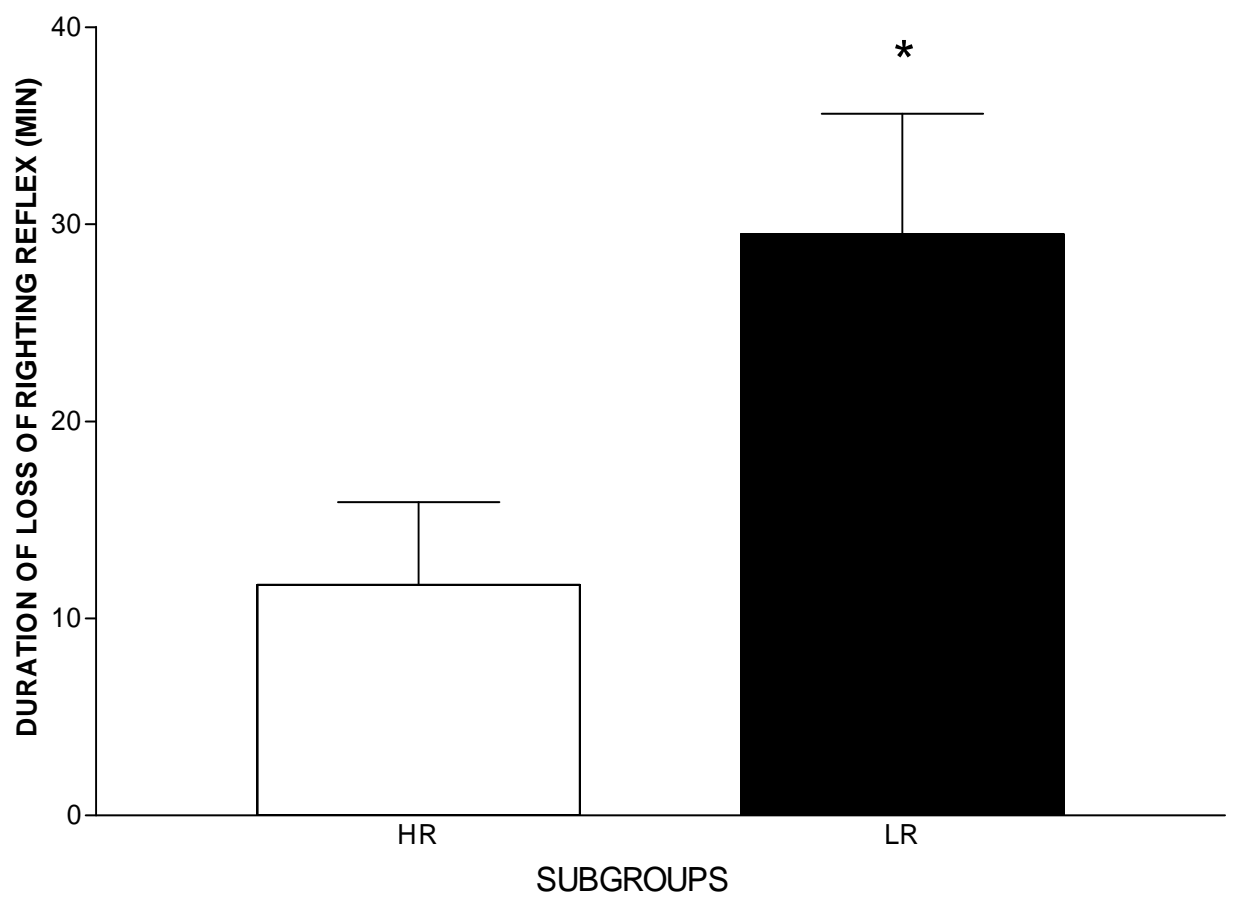

Figure 2. Hypnotic effect (sleeping time) induced by diazepam (8 mg/kg, i.p.) in the high- (HR) and low-rearing (LR) rat groups. Sleeping time was scored as the time interval between the loss and recovery of the righting reflex. $\mathrm{N}=9$ for the $\mathrm{HR}$ and $N=13$ for the LR group. ${ }^{*} p=0.04$, two-tailed, unpaired Student's t test.

Table 3. Behavior of rats submitted to the open field test under two different levels of stimulation.

\begin{tabular}{ccc}
\hline Group & Rearings & Ambulation \\
\hline Lights on & $24.8 \pm 2.9$ & $74.5 \pm 9.1$ \\
Lights off & $24.6 \pm 2.4$ & $53.6 \pm 4.6^{*}$ \\
\hline
\end{tabular}

The values are expressed as the means \pm S.E.M. $\mathrm{N}=12$ for each group. "Lights off" represents the exposure to only the room illumination and "Lights on" represents the exposure to illumination from six $60 \mathrm{~W}$ light bulbs located above the arena plus the room illumination. ${ }^{*} \mathrm{p}=0.02$, two-tailed, Mann-Whitney U test.

off) was the same as those observed in the population means obtained in other selections that had been performed (Table 1). The rats tested with the open field lights on ambulated more ( $p=0.02$, two-tailed, MannWhitney $U$ test) than those tested with the open field lights off. Although the number of rats used in this experiment was small, the number of rats designated as HR and as LR under the two levels of stimuli did not differ significantly (open field lights on: $\mathrm{HR}=4 / 12$ [33.3\%], $\mathrm{LR}=3 / 12$ [25\%]; open field lights off: $\mathrm{HR}=4 / 12$ $[33.3 \%], \mathrm{LR}=3 / 12$ [25\%]).

\subsection{Effects of Open Field Re-Test on HR and LR Groups}

The difference in the frequency of rearings between the HR and LR groups remained significant in the re-test session ( $p=0.0002$, two-tailed, Mann-Whitney U test) (Table 4). A significant decrease in the rearing frequency was observed in the LR rats when comparing the test and re-test sessions (HR/test versus re-test, $\mathrm{p}=0.084$, two-tailed; $\mathrm{LR} /$ test versus re-test, $\mathrm{p}=0.01$, two-tailed, Wilcoxon signed rank test). Linear regression and correlation statistical analyses of the rearing frequency showed a significant correlation between the numbers of rearings in the test and re-test sessions $(\mathrm{p}<0.0001)$. There were no significant differences in the amount of ambulation between the HR and LR groups in the test session ( $p=0.070$, two-tailed, Mann-Whitney U test) or in the re-test session $(\mathrm{p}=0.13$, two-tailed, Mann-Whitney U test).

\subsection{Plasma ACTH and Serum Corticosterone Levels in HR and LR Rats}

The number of rearings of the HR and LR groups of rats used to determine hormones levels were: HR group = $37.4 \pm 2.0$ rearings, mean \pm S.E.M, $\mathrm{N}=8$ and LR group $=$ $12.0 \pm 1.4$ rearings for the ACTH assay. HR group $=33.3 \pm$ 2.0 rearings, $\mathrm{N}=10$ and $\mathrm{LR}$ group $=13.7 \pm 1.4, \mathrm{~N}=10$ for the corticosterone assay.

The plasma ACTH (HR group: $12.5 \pm 1.8 \mathrm{pg} / \mathrm{mL}$, mean \pm S.E.M., $\mathrm{N}=8$; LR group: $18.4 \pm 3.1, \mathrm{~N}=8 ; \mathrm{t}=$ $0.50, \mathrm{df}=14, \mathrm{p}>0.05)$ and serum corticosterone (HR group: $166.6 \pm 36.8 \mathrm{ng} / \mathrm{mL}$, mean \pm S.E.M., $\mathrm{N}=10$; $\mathrm{LR}$ group $137.9 \pm 25.1, \mathrm{~N}=10 ; \mathrm{t}=0.64, \mathrm{df}=18, \mathrm{p}>0.05$ ) levels did not differ between the rat groups. 
Table 4. Rearing frequency of high- (HR) and low-rearing (LR) rats during the initial open field selection session (test) and a follow-up open field session (re-test).

\begin{tabular}{ccccc}
\hline Groups & \multicolumn{2}{c}{ Test } & \multicolumn{2}{c}{ Re-test } \\
\hline & Rearings & Ambulation & Rearings & Ambulation \\
HR & $\begin{array}{c}33.6 \pm 1.3 \\
(\mathrm{~N}=10)\end{array}$ & $75.1 \pm 6.7$ & $27.8 \pm 3.0$ & $51.6 \pm 7.9$ \\
LR & $\begin{array}{c}14.7 \pm 1.3 \\
(\mathrm{~N}=7)\end{array}$ & $65.2 \pm 3.9$ & $9.0 \pm 2.1$ & $46.7 \pm 10.9$ \\
\hline
\end{tabular}

The values are expressed as the means \pm S.E.M. The HR and LR rats were re-exposed to the open field 15 days after the open field selection session. test session: $H R$ versus LR, $p<0.0001$, re-test session: HR versus LR, $p=$ 0.0002 , two-tailed, Mann-Whitney U test. LR group: test versus re-test session: $\mathrm{p}=0.01$, Wilcoxon signed rank test.

\section{7. $\left[{ }^{3} \mathbf{H}\right]-$ Flunitrazepam Binding Assay}

There was a statistically significant lower density of $\left[{ }^{3} \mathrm{H}\right]-\mathrm{FNT}$ bound to the $\mathrm{GABA}_{\mathrm{A}}$ receptor in the hippocampus of the LR rats than in the HR rats at both ligand concentrations that were assayed ( $p=0.01$, two-tailed, Student's t test) (Figure 3).

\section{Discussion}

The frequency of rearings in the open field test in our outbred stock of Wistar rats showed a statistically normal distribution. Moreover, the average number of rearings in the population was highly reproducible, as shown by the results of several independent selection tests using rats from different litters and tested at different times of the year. The difference in the mean number of rearings between the HR and LR groups was also very consistent throughout these independent selection trials (Table 1). This consistency is important because each drug was tested on HR and LR groups derived from different litters and during different months of the year.

The difference in the frequency of rearings between the HR and LR rats in the test/re-test open field sessions remained significant, indicating that rearing can be considered a phenotype. The number of rearings decreased in both the HR and LR groups when comparing test versus re-test open field sessions. This decrease is expected because re-exposure to the same level of stimulation would not have the same intensity (i.e. the novelty was not the same as in the test session).

In mouse strains genetically selected for different rearing behavior in the open field, there was a positive correlation between ambulation and the number of rearings [3]. Borta and Schwarting [38] have also found out a positive relationship between the total number of rearings and locomotion in their selected groups of rats. A similar relationship was not observed in all the HR and LR groups selected in our experiments (Table 1). The lack of a difference in locomotion between some of the HR

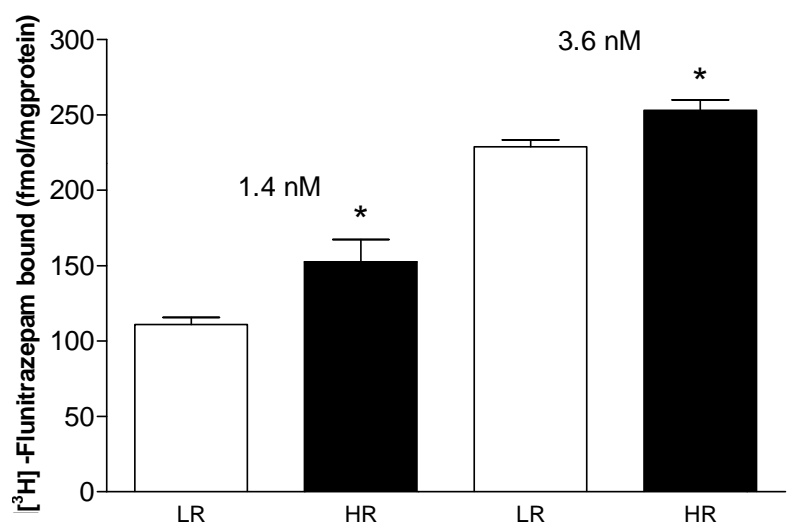

Figure 3. $\left[{ }^{3} \mathrm{H}\right]-$ Flunitrazepam bound at two concentrations (1.4 and $3.6 \mathrm{nM}$ ) to hippocampal membranes from high(HR) and low-rearing (LR) groups of rats selected in the open field test. HR group $=37.7 \pm 2.8$ rearings, mean \pm S.E.M., $N=7$ and $L R$ group $=13.3 \pm 1.4$ rearings, $N=8$ at $1.4 \mathrm{nM}$. HR group $=32.2 \pm 0.7$ rearings, $\mathrm{N}=7$ for the $\mathrm{HR}$ and $L R$ group $=13.0 \pm 1.1, \mathrm{~N}=9$ at $3.6 \mathrm{nM}$. ${ }^{*} \mathrm{p}=0.01$, two-tailed, unpaired Student's t test.

and LR groups in the present experiment was probably detected because these rats were tested at different times of the year, which suggests that differences in locomotion between HR and LR rearing individuals may depend on the time of year. These differences may also indicate a distinct neural basis for locomotion.

Of all the convulsant drugs tested only DMCM, a benzodiazepine inverse agonist [15,19,36,37], induced differential clonic convulsions between the HR and LR groups. The lower convulsant dose $50 \%$ obtained in the LR rats indicates a higher susceptibility to the drug compared with that of the HR rats. The convulsant dose $50 \%$ for DMCM obtained herein is in accordance with a previously convulsant dose $50 \%$ for clonic convulsions obtained in inbred male Wistar rats [19]. The higher susceptibility to clonic convulsions induced by DMCM and the longer sleeping time induced by diazepam (Figure 2) observed in the LR group suggest differences from the HR rats with respect to the benzodiazepine allosteric site in the $\mathrm{GABA}_{\mathrm{A}}$ receptor.

The present study showed that HR rats have a higher density of benzodiazepine binding sites in the hippocampus, as measured by $\left[{ }^{3} \mathrm{H}\right]$-FNT binding to the $\mathrm{GABA}_{\mathrm{A}}$ receptor (Figure 3). The higher density of the benzodiazepine binding sites in the hippocampus of the HR group may explain their lower sensitivity to DMCM-induced clonic convulsion (higher convulsant dose 50\%). The higher density of hippocampal benzodiazepine binding sites in the HR rats may require a higher concentration of $\mathrm{DMCM}$ at the receptors to decrease the inhibitory effect of GABA.

The hippocampus does not seem to be involved in the sleep induced by diazepam. Therefore, the difference in 
the density of hippocampal $\left[{ }^{3} \mathrm{H}\right]$-FNT binding between the HR and LR groups may not be involved in the longer sleeping time induced by diazepam in the LR rats. Other brain regions involved in the triggering and maintenance of sleep should be studied to determine possible differences between the two groups with respect to the density of benzodiazepine binding sites.

Chronic exposure to stress levels of corticosterone has been shown to alter the mRNA expression levels of six subunits $\left(\alpha_{1}, \alpha_{2}, \beta_{1}, \beta_{2}, \beta_{3}\right.$ and $\left.\gamma_{2}\right)$ of the $\mathrm{GABA}_{\mathrm{A}}$ receptor in regions of the rat hippocampus [39]. The expression changes involved both increases and decreases depending on the hippocampal region and particular subunit. Additionally, long-term adrenalectomy has been shown to decrease the number of rearings in the open field in rats [40]. Therefore, these data suggest that a difference in corticosterone levels between the HR and LR groups could underlie their behavioral differences. The lack of differences in the plasma ACTH and serum corticosterone levels between the HR and LR groups, however does not support the involvement of these hormones in the difference in rearing behavior or in the susceptibility to the clonic convulsions induced by DMCM. Naive rats submitted to different levels of stimulation in the open field test did not differ in the number of rearings. Accordingly, the number of HR and LR rearing individuals under both levels of stimulation was not different. Therefore, these behavioral and hormonal data rule out an influence of the reaction to stress and stress hormone on the differences in the rearing frequency between the selected groups.

The $\mathrm{GABA}_{\mathrm{A}}$ receptor most typically comprises an assembly of five proteins subunits, two $\alpha$ two $\beta$ and one $\gamma$ subunit $[16,17]$. These subunits have different isoforms $\left(\alpha_{1-6}, \beta_{1-3}\right.$ and $\left.\gamma_{1-3}\right)$ which allows the assembly of multiple receptors with different compositions [41]. Benzodiazepine agonists and inverse agonists have been shown to bind to the interface of $\alpha$ and $\gamma$ subunits $[16,17]$. Although there is a great complexity in the distribution and composition of the $\mathrm{GABA}_{\mathrm{A}}$ receptor throughout brain regions most of the $\mathrm{GABA}_{\mathrm{A}}$ receptors contain the $\alpha_{1}$ subunit [16]. The benzodiazepine inverse agonist DMCM can be anxiogenic $[42,43]$ or a very potent convulsant agent $[18,19,21,23]$ depending on the dose given. The drug binds to brain membranes with high affinity, and these brain sites are distributed unevenly within brain regions. The hippocampus and frontal cortex contain the highest specific binding [36]. The mechanism of action of DMCM involves a decrease of $\mathrm{GABA}_{\mathrm{A}}$ chloride channel opening frequency, which is opposite the agonist mechanism of action [15]. DMCM has a higher affinity for $\alpha_{1} \beta_{2} \gamma_{2} \mathrm{GABA}_{\mathrm{A}}$ receptors $[44,45]$ when compared with other $\alpha$ subunits [46] and acts as an inverse agonist, decreasing the GABA response at $\alpha_{1} \beta_{2} \gamma_{2} \mathrm{GABA}_{\mathrm{A}}$ receptors
$[44,47,48]$. $\mathrm{GABA}_{\mathrm{A}}$ receptors containing the $\alpha_{1}$ subunit have been related to the anticonvulsant and sedative effects of benzodiazepines agonists [17,49]; moreover, DMCM lacks its convulsant effect in knock-in mice con taining point-mutated $\alpha_{1}(\mathrm{H} 101 \mathrm{R})-\mathrm{GABA}_{\mathrm{A}}$ receptors [44]. Both diazepam, a full benzodiazepine agonist for all $\mathrm{GABA}_{\mathrm{A}}$ receptors, and zolpidem, an agonist with a higher affinity for $\mathrm{GABA}_{\mathrm{A}}$ receptors containing the $\alpha_{1}$ subunit [50], at dose of $2.5 \mathrm{mg} / \mathrm{kg}$, decrease the duration of rearings both at and off the wall in the open field test [9]. These data suggest a preeminent role of the $\alpha_{1}$-containing $\mathrm{GABA}_{\mathrm{A}}$ receptor in rearing behavior. Therefore, our present data suggest that $\mathrm{GABA}_{\mathrm{A}}$ receptors containing the $\alpha_{1}$ subunit are involved in the inter-individual differences in rearing behavior.

According to Ableitner and Herz [51], the intravenously administration of DMCM to rats elicits seizures very similar to those elicited by electrical kindling of limbic structures, which includes forelimb clonus and rearing. The same study demonstrated that DMCM induced an increase in the local cerebral glucose utilization (LCGU) in several brain structures, including those belonging to the limbic system, such as the hippocampus. A comparison of the effects of FG 7142, a proconvulsant benzodiazepine inverse agonist that does not increase hippocampal LCGU, with those of DMCM suggests that the hippocampus may be of major importance for the initiation of seizures induced by DMCM [51]. In addition, novelty has been shown to be related to the induction of hippocampal long-term depression [52] and neurogenesis [53]. Therefore, a straight relationship among hippocampal $\mathrm{GABA}_{\mathrm{A}} /$ allosteric benzodiazepine site receptors, clonic convulsion and rearing behavior is supported by the above data, our previous observations with respect to the activity of $\mathrm{K}^{+}$-stimulated p-nitrophenylphosphatase in the hippocampus [23] and the pharmacological and biochemical differences observed between the HR and LR groups in this study.

The lack of differences between HR and LR rats with respect to the susceptibility to clonic convulsions induced by the other convulsant drugs tested indicated that the activity of glutamate decarboxylase as well as the GABA and chloride channel binding sites in the $\mathrm{GABA}_{\mathrm{A}}$ recaptor do not differ between these two groups. Tonic convulsions are generated in the brainstem [54]. The lack of differences between HR and LR groups with respect to the susceptibility to DMCM-induced tonic convulsions suggests that differences in the $\mathrm{GABA}_{\mathrm{A}}$ receptor between the two groups are not found in the brainstem.

\section{Conclusion}

In conclusion, the data obtained in this study suggest that the differences in rearing behavior induced by novelty 
are related to differences in the hippocampal allosteric benzodiazepine site in the $\mathrm{GABA}_{\mathrm{A}}$ receptor. Further work is needed to determine possible differences in the $\mathrm{GABA}_{\mathrm{A}}$ receptor assembly between the groups of HR and LR rats.

\section{Acknowledgements}

This work was supported by Associação Fundo de Incentivo à Psicofarmacologia (AFIP). Rosana Alves is the recipient of a fellowship from Fundação de Amparo à Pesquisa do Estado de São Paulo (FAPESP). We thank Marcela I. Venditti Sarudiansky for her help in the preparation of this manuscript and Drs. Debora Suchecki and Magda Bignotto for their help with the hormone assays.

\section{REFERENCES}

[1] W. E. Crusio, "Genetic Dissection of Mouse Exploratory Behavior," Behavioural Brain Research, Vol. 125, No. 1-2, 2001, pp. 127-132. doi:10.1016/S0166-4328(01)00280-7

[2] J. H. F. van Abeelen, "Genetic Analysis of Behavioural Responses to Novelty in Mice," Nature, Vol. 254, No. 5497, 1975, pp. 239-241. doi:10.1038/254239a0

[3] J. H. F. van Abeelen, "Rearing Responses and Locomotor Activity in Mice: Single-Locus Control," Behavioral Biology, Vol. 19, No. 3, 1977, pp. 401-404. doi:10.1016/S0091-6773(77)91826-0

[4] H. van Lier, W. H. Drinkenburg and A. M. L. Coenen, "Strain Differences in Hippocampal EEG Are Related to Strain Differences in Behaviour in Rats," Physiology \& Behavior, Vol. 78, No. 1, 2003, pp. 91-97. doi:10.1016/S0031-9384(02)00893-4

[5] D. K. Hannesson, J. Howland, M. Pollock, P. Mohapel, A. E. Wallace and M. E. Corcoran, "Dorsal Hippocampal Kindling Produces a Selective and Enduring Disruption of Hippocampally Mediated Behavior," The Journal of Neuroscience, Vol. 21, No. 12, 2001, pp. 4443-4450.

[6] J. Ma, S. M. Brudzynski and L. W. S. Leung, "Involvement of the Nucleus Accumbens-Ventral Pallidal Pathway in Posictal Behavior Induced by a Hippocampal after Discharge in Rats," Brain Research, Vol. 739, No. 1-2, 1996, pp. 26-35. doi:10.1016/S0006-8993(96)00793-7

[7] J. Ma, S. M. Brudzynski and L. W. S. Leung, "A Role of Subicular and Hippocampal after Discharges in Initiation of Locomotor Activity in Rats," Brain Research, Vol. 193, No. 1-2, 1998, pp. 112-118. doi:10.1016/S0006-8993(98)00165-6

[8] R. J. Racine, "Modification of Seizure Activity by Electrical Stimulation: II. Motor Seizure," Electroencephlography and Clinical Neurophysiol, Vol. 32, No. 3, 1972, pp. 281-294. doi:10.1016/0013-4694(72)90177-0

[9] H. van Lier, H. I. Drinkenburg, Y. J. W. van Eeten and A. M. L. Coenen, "Effects of Diazepam and Zolpidem on EEG Beta Frequencies Are Behavior-Specific in Rats,"
Neuropharmacology, Vol. 47, No. 2, 2004, pp. 163- 174. doi:10.1016/j.neuropharm.2004.03.017

[10] C. Belzung, "Hippocampal Mossy Fibres: Implication in Novelty Reactions or in Anxiety Behaviors?" Behavioral Brain Research, Vol. 51, No. 2, 1992, pp. 149-155. doi:10.1016/S0166-4328(05)80208-6

[11] W. E. Crusio, H. Schwegler, I. Brust and J. H. van Abeelen, "Genetic Selection for Novelty-Induced Rearing Behavior in Mice Produces Changes in Hippocampal Mossy Fiber Distributions," Journal of Neurogenetics, Vol. 5, No. 1, 1989, pp. 87-93.

[12] Z. Hausheer-Zarmakupi, D. P. Wolfer, M. C. LeisingerTrigona and H. P. Lipp, "Selective Breeding for Extremes in Open-Field Activity of Mice Entails a Differentiation of Hippocampal Mossy Fibers, Behavior Genetics, Vol. 26, No. 2, 1996, pp. 167-176. doi:10.1007/BF02359894

[13] P. Roullet and J. M. Lassalle, "Genetic Variation, Hippocampal Mossy Fibres Distribution, Novelty Reactions and Spatial Representation in Mice," Behavioral Brain Research, Vol. 41, No. 1, 1990, pp. 61-70. doi:10.1016/0166-4328(90)90054-I

[14] S. J. Enna and N. G. Bowery, "GABA $\mathrm{GA}_{\mathrm{B}}$ Receptor Alterations as Indicators of Physiological and Pharmacological Function," Biochemical Pharmacology, Vol. 68, No. 8, 2004, pp. 1541-1548. doi:10.1016/j.bcp.2004.06.037

[15] G. A. R. Johnston, "GABA A Receptor Pharmacology," Pharmacology and Therapeutics, Vol. 69, No. 3, 1996, pp. 173-198. doi:10.1016/0163-7258(95)02043-8

[16] E. R. Korpi, G. Grunder and H. Luddens, "Drug Interactions at $\mathrm{GABA}_{\mathrm{A}}$ Receptors," Progress in Neurobiology, Vol. 37, No. 2, 2002, pp. 113-159. doi:10.1016/S0301-0082(02)00013-8

[17] H. Mohler, J. M. Fritschy and U. Rudolph, "A New Benzodiazepine Pharmacology," Journal of Pharmacology and Experimental Therapeutics, Vol. 300, No. 1, 2002, pp. 2-8. doi:10.1124/jpet.300.1.2

[18] M. Vergnes, A. Boehrer, S. Reibel, S. Simler and C. Marescaux, "Selective Susceptibility to Inhibitors of GABA Synthesis and Antagonists of $\mathrm{GABA}_{\mathrm{A}}$ Receptors in Rats with Genetic Absence Epilepsy," Experimental Neurology, Vol. 161, No. 2, 2000, pp. 714-723. doi:10.1006/exnr.1999.7302

[19] M. Vergnes, A. Boehrer, X. He, H. Greney, M. Dontenwill, J. Cook and C. Marescaux, "Differential Sensitivity to Inverse Agonist of $\mathrm{GABA}_{\mathrm{A}} /$ Benzodiazepine Receptors in Rats with Genetic Absence-Epilepsy," Epilepsy Research, Vol. 47, No. 1-2, 2001, pp. 43-53. doi:10.1016/S0920-1211(01)00292-3

[20] M. Netopilova, J. Drsata, R. Haugvicova, H. Kubova and P. Mares, "Inhibition of Glutamate Decarboxylase Activity by 3-Mercaptopropionic Acid Has Different Time Course in the Immature and Adult Rat Brains," Neuroscience Letters, Vol. 226, No. 1, 1997, pp. 68-70. doi:10.1016/S0304-3940(97)00241-3

[21] G. De Sarro, A. Chimirri, M. Zappala, P. Guisti, M. Lipartiti and A. De Sarro, "Azirinol[1,2-d][1,4]benzodiazepine Derivatives and Related 1,4-benzodiazepines as An- 
ticonvulsant Agents in DBA/2 Mice," General Pharmacology, Vol. 27, No. 7, 1996, pp. 1155-1162. doi:10.1016/S0306-3623(96)00049-3

[22] P. Kwan, G. J. Sills and M. J. Brodie, "The Mechanisms of Action of Commonly Used Antiepileptic Drug," Pharmacology \& Therapeutics, Vol. 90, No. 1, 2001, pp. 2134. doi:10.1016/S0163-7258(01)00122-X

[23] R. Alves, J. G. B. Carvalho and M. A. C. Benedito, "High and Low Rearing Subgroups of Rats Selected in the Open Field Differ in the Activity of

$\mathrm{K}^{+}$-stimulated-p-nitrophenylphosphatase in the Hippocampus," Brain Research, Vol. 1058, No. 1-2, 2005, pp. 178182. doi:10.1016/j.brainres.2005.08.005

[24] R. J. Hernández, " $\mathrm{Na}^{+} / \mathrm{K}^{+}$-ATPase Regulation by Neurotransmitters," Neurochemistry International, Vol. 20, No. 1, 1992, pp. 1-10. doi:10.1016/0197-0186(92)90119-C

[25] J. W. Phillis, " $\mathrm{Na}^{+} / \mathrm{K}^{+}$-ATPase as an Effector of Synaptic Transmission," Neurochemistry International, Vol. 20, No. 1, 1992, pp. 19-22. doi:10.1016/0197-0186(92)90121-7

[26] E. S. Vizi and F. Oberfrank, " $\mathrm{Na}^{+} / \mathrm{K}^{+}$-ATPase, Its Endogenous Ligands and Neurotransmitter Release," Neurochemistry International, Vol. 20, No. 1, 1992, pp. 11-17. doi:10.1016/0197-0186(92)90120-G

[27] C. Vaillend, S. E. Mason, M. F. Cuttle and B. E. Alger, "Mechanisms of Neuronal Hyperexcitability Caused by Partial Inhibition of $\mathrm{Na}^{+}-\mathrm{K}^{+}$-ATPases in the Rat CA1 Hippocampal Region," Journal of Neurophysiology, Vol. 88, No. 6, 2002, pp. 2963-2978. doi:10.1152/jn.00244.2002

[28] D. S. Eidman, M. A. C. Benedito and J. R. Leite, "Daily Changes in Pentylenetetrazol-Induced Convulsions and Open-Field Behavior in Rats," Physiology \& Behavior, Vol. 47, No. 5, 1990, pp. 853-856. doi:10.1016/0031-9384(90)90008-R

[29] J. T. Litchfield Jr. and F. Wilcoxon, "A Simplified Method of Evaluating Dose-Effect Experiments," Journal of Pharmacology and Experimental Therapeutics, Vol. 96, No. 2, 1949, pp. 99-113.

[30] M. B. Contó, D. C. Hipólide, J. G. de Carvalho and M. A. C. Venditti, "Rats with Different Thresholds for DMCMInduced Clonic Convulsions Differ in the Sleep-Time of Diazepam and $\left[{ }^{3} \mathrm{H}\right]-\mathrm{Ro}$ 15-4513 Binding," Epilepsy Research, No. 2-3, 2011, pp. 216-222.

[31] R. Rupprecht, "Neuroactive Steroids: Mechanism of Action and Neuropsychopharmacological Properties," Psychoneuroendocrinology, Vol. 28, No. 2, 2003, pp. 139168. doi:10.1016/S0306-4530(02)00064-1

[32] M. L. Andersen, P. J. F. Martins, V. D’Almeida, M. Bignotto and S. Tufik, "Endocrinological and Catecholaminergic Alterations during Sleep Deprivation and Recovery in Male Rats," Journal of Sleep Research, Vol. 14, No. 1, 2005, pp. 83-90. doi:10.1111/j.1365-2869.2004.00428.x

[33] D. Suchecki, P. A. Tiba and S. Tufik, "Paradoxical Sleep Deprivation Facilitates Subsequent Corticosterone Response to a Mild Stressor in Rats," Neuroscience Letters, Vol. 320, No. 1-2, 2002, pp. 45-48.

\section{doi:10.1016/S0304-3940(02)00024-1}

[34] M. S. Kafka, M. A. Benedito, J. A. Blendy and N. S. Tokola, "Circadian Rhythms in Neurotransmitter Receptors in Discrete Rat Brain Regions," Chronobiology International, Vol. 3, No. 2, 1986, pp. 91-100. doi: $10.3109 / 07420528609066353$

[35] O. H. Lowry, N. J. Rosebrough, A. L. Farr and R. J. Randall, "Protein Measurement with the Folin Phenol Reagent," Journal of Biological Chemistry, Vol. 193, No. 1, 1951, pp. 265-275.

[36] C. Braestrup, M. Nielsen and T. Honoré, "Binding of $\left[{ }^{3} \mathrm{H}\right] \mathrm{DMCM}$, a Convulsive Benzodiazepine Ligand, to Rat Brain Membranes: Preliminary Studies," Journal of Neurochemistry, Vol. 41, No. 2, 1983, pp. 454-465. doi:10.1111/j.1471-4159.1983.tb04763.x

[37] R. F. Squires, E. Saederup, J. N. Crawley, P. Skolnick and S. M. Paul, "Convulsant Potencies of Tetrazoles Are Highly Correlated with Actions on GABA/Benzodiazepine/Picrotoxin Receptor Complexes in Brain," Life Sciences, Vol. 35, No. 14, 1984, pp. 1439-1444. doi:10.1016/0024-3205(84)90159-0

[38] A. Borta and R. W. Schwarting, "Post-Trial Treatment with the Nicotinic Agonist Metanicotine: Differential Effects in Wistar Rats with High Versus Low Rearing Activity," Pharmacology Biochemistry and Behavior, Vol. 80, No. 4, 2005, pp. 541-548. doi:10.1016/j.pbb.2004.12.014

[39] M. Orchinik, N. G. Weiland and B. S. McEwen, "Chronic Exposure to Stress Levels of Corticosterone Alters $\mathrm{GABA}_{\mathrm{A}}$ Receptor Subunit mRNA Levels in Rat Hippocampus," Molecular Brain Research, Vol. 34, No. 1, 1995, pp. 29-37. doi:10.1016/0169-328X(95)00118-C

[40] A. Islam, B. Henriksson, A. Mohammed, B. Winblad and A. Adem, "Behavioural Deficits in Adult Rats Following Long-Term Adrenaletomy," Neuroscience Letters, Vol. 194, No. 1-2, 1995, pp. 49-52. doi:10.1016/0304-3940(95)11724-B

[41] S. Pirker, C. Schwarzer, A. Wieselthaler, W. Sieghart and G. Sperk, "GABA A Receptors: Immunocytochemical Distribution of 13 Subunits in the Adult Rat Brain," Neuroscience, Vol. 101, No. 4, 2000, pp. 815-850.

[42] J. C. Cole, M. Hillmann, D. Seidelmann, M. Klewer and G. H. Jones, "Effects of Benzodiazepine Receptor Partial Inverse Agonists in the Elevated Plus Maze Test of Anxiety in the Rat," Psychopharmacology, Vol. 121, No. 1, 1995, pp. 118-126. doi:10.1007/BF02245598

[43] R. E. Grahn, B. A. Kalman, F. X. Brennan, L. R. Watkins and S. F. Maier, "The Elevated Plus-Maze Is Not Sensitive to the Effect of Stressor Controllability in Rats," Pharmacology Biochemistry and Behavior, Vol. 52, No. 3, 1995, pp. 565-570. doi:10.1016/0091-3057(95)00141-I

[44] F. Crestani, R. Assandri, M. Tauber, J. R. Martin and U. Rudolph, "Contributions of the Alpha1-GABA Receptor $_{\mathrm{A}}$ Subtype to the Pharmacological Actions of Benzodiazepine Site Inverse Agonists," Neuropharmacology, Vol. 43, No. 4, 2002, pp. 679-684. doi:10.1016/S0028-3908(02)00159-4

[45] J. M. C. Derry, S. M. J. Dunn and M. Davies, "Identifica- 
tion of a Residue in the Gamma-Aminobutyric Acid Type A Receptor Alpha Subunit That Differentially Affects Diazepam-Sensitive and -Insensitive Benzodiazepine Site Binding," Journal of Neurochemistry, Vol. 88, No. 6, 2004, pp. 1431-1438.

doi:10.1046/j.1471-4159.2003.02264.x

[46] H. Luddens and W. Wisden, "Function and Pharmacology of Multiple GABA A Receptor Subunits," Trends in Pharmacological Sciences, Vol. 12, No. 2, 1991, pp. 4951. doi:10.1016/0165-6147(91)90495-E

[47] G. Puia, S. Vicini, P. Seeburg and E. Costa, "Influence of Recombinant Gama-Aminobutyric Acid-A Receptor Subunit Composition on the Action of Allosteric Modulators of Gamma-Aminobutyric Acid-Gated Cl-Currents," Molecular Pharmacology, Vol. 39, No. 6, 1991, pp. 691-696.

[48] A. Stevenson, P. B. Wingrove, P. J. Whiting and K. A. Wafford, "Beta-Carboline Gamma-Aminobutyric Acid $_{\mathrm{A}}$ Receptor Inverse Agonists Modulate Gamma-Aminobutyric Acid via the Loreclezole Binding Site as Well as the Benzodiazepine Site," Molecular Pharmacology, Vol. 48, No. 6, 1995, pp. 965-969.

[49] J. E. Kralic, T. K. O’Buckley, R. T. Khisti, C. W. Hodge, G. E. Homanics and A. L. Morrow, "GABA $\mathrm{G}_{\mathrm{A}}$ Receptor Alpha-1 Subunit Deletion Alters Receptor Subtype Assembly, Pharmacological and Behavioral Responses to Benzodiazepines and Zolpidem," Neuropharmacology, Vol. 43, No. 4, 2002, pp. 685-694.

$$
\text { doi:10.1016/S0028-3908(02)00174-0 }
$$

[50] U. Rudolph, F. Crestani, D. Benke, I. Brunig, J. A. Benson, J. M. Fritschy, J. R. Martin, H. Bluethmann and H. Mohler, "Benzodiazepine Actions Mediated by Specific $\gamma$-Aminobutyric Acid $_{\mathrm{A}}$ Receptor Subtypes," Nature, Vol. 401, No. 6755, 1999, pp. 796-800. doi:10.1038/44579

[51] A. Ableitner and A. Herz, "Changes in Local Cerebral Glucose Utilization Induced by the Beta-Carbolines FG 7142 and DMCM Reveal Brain Structures Involved in the Control of Anxiety and Seizure Activity," The Journal of Neuroscience, Vol. 7, No. 4, 1987, pp. 1047-1055.

[52] D. Manahan-Vaughan and K. H. Braunewell, "Novelty Acquisition Is Associated with Induction of Hippocampal Long-Term Depression," Proceedings of the National Academy of Sciences of the United States of America, Vol. 96, No. 15, 1999, pp. 8739-8744. doi:10.1073/pnas.96.15.8739

[53] V. Lemaire, C. Aurousseau, M. Le Moal and D. N. Abrous, "Behavioural Trait of Reactivity to Novelty Is Related to Hippocampal Neurogenesis," European Journal of Neuroscience, Vol. 11, No. 11, 1999, pp. 4006-4014. doi:10.1046/j.1460-9568.1999.00833.x

[54] K. Gale, "Progression and Generalization of Seizure Discharge: Anatomical and Neurochemical Substrates," Epilepsia, Vol. 29, No. 2, 1988, pp. S15-S34. doi:10.1111/j.1528-1157.1988.tb05795.x 